Artigo original

Hegemonia - Revista Eletrônica de Relações Internacionais do Centro Universitário Unieuro ISSN: 1809-1261

UNIEURO, Brasília, número 5, 2010

Recebido em: 6/11/2009

Revisado em: 2/12/009

Aprovado em: 19/2/2010

\title{
O PARLAMENTO DO MERCOSUL: REFLEXÕES SOBRE A SUA SITUAÇÃO ATUAL E PERSPECTIVAS
}

MATEUS, Tatiane Rodrigues ${ }^{1}$

Resumo: O estudo propõe uma reflexão sobre a integração regional, especificamente sobre o MERCOSUL (Mercado Comum do Sul) e sua importância em nível regional e internacional. De forma sucinta, busca apontar a relevância do Parlamento do MERCOSUL como fórum de discussões de questões pertinentes ao processo de integração regional e efetivação da incorporação normativa dos ordenamentos dos Estados-Parte, trazendo consigo o aperfeiçoamento e consolidação do bloco.

Palavras-chave: Mercosul; Parlamento;Brasil.

Abstract: This study proposes a reflection about regional integration, mainly about MERCOSUL (South Common Mercado) and its important position in international and regional level. It points the MERCOSUL's Parliament's relevance as a regional integration questions discussions forum and States-Part's ordainments normative incorporation, taking its MERCOSUL's perfection e consolidation.

Key-words: Mercosur; Parlament; Brazil.

\section{Introdução}

Após o fim da Guerra Fria, o mundo deixou de ser dividido em blocos antagônicos e, conseqüentemente, intensificaram-se os fluxos do comércio e o estreitamento das relações políticas e econômicas entre Estados e sociedades. Por outro lado, os avanços tecnológicos e nos meios de comunicação, implicaram uma "reestruturação da economia mundial", com base 
Artigo original

Hegemonia - Revista Eletrônica de Relações Internacionais do Centro Universitário Unieuro ISSN: 1809-1261

UNIEURO, Brasília, número 5, 2010

nas tendências à multilateralização e regionalização do comércio.

O estudo propõe uma reflexão sobre a integração regional, especificamente sobre o MERCOSUL (Mercado Comum do Sul) e sua importância em nível regional e internacional. De forma sucinta, busca apontar a relevância do Parlamento do MERCOSUL como fórum de discussões de questões pertinentes ao processo de integração regional e efetivação da incorporação normativa dos ordenamentos dos Estados-Parte, trazendo consigo o aperfeiçoamento e consolidação do bloco.

Esse trabalho tem como objetivo principal analisar a importância do Parlamento do MERCOSUL para o Bloco e sua consolidação. Como objetivo específico, pretende-se: compreender o contexto e razões do processo de integração; conhecer a dinâmica do bloco nas Relações Internacionais e por fim analisar a evolução do MERCOSUL com a criação do Parlamento.

Nesse sentido, o problema central do estudo refere-se à importância a constituição de um Parlamento, que de fato possa atender às necessidades do MERCOSUL e dos mercosulinos. Daí as perguntas: qual o papel da integração regional para o intercâmbio comercial político e cultural? Como a internalização de leis nacionais pode interferir neste intercâmbio?Como o Parlamento do MERCOSUL pode aproximar os nacionais de seus Estados- Parte entre si e fazê-los sentir-se parte do bloco?Quais os aspectos positivos da criação do Parlamento neste Bloco?

Em se tratando de uma reflexão sobre integração regional e suas implicações, os referenciais conceituais e teóricos do estudo partiram das formulações de Herz \& Hoffman (1994), Souto Maior (2003), Albuquerque (2005) e Ramalho (2008).

Esse estudo justifica-se por buscar analisar as implicações da criação do Parlamento Mercosulino, além de salientar o valor dos arranjos regionais e sua importância para as relações internacionais, que não se detém aos líderes de Estados, mas que se torna acessível aos cidadãos nacionais dos Estados-Parte através da representação de seus parlamentares. $\mathrm{Na}$ medida em que esse escopo de relações engendrado pelo processo de integração na América 
Artigo original

Hegemonia - Revista Eletrônica de Relações Internacionais do Centro Universitário Unieuro ISSN: 1809-1261

UNIEURO, Brasília, número 5, 2010

do Sul e todos os recursos criados para viabilizá-la gera arranjos, negociações e conflitos estudá-lo é da maior relevância para o conhecimento das relações internacionais.

$\mathrm{O}$ estudo foi desenvolvido a partir das seguintes partes. Na primeira, analisamos o conceito de integração e de que forma o processo a que ele se refere se constitui no mundo global. Na seqüencia, examinamos o contexto que gerou a criação do MERCOSUL na América do Sul. Na segunda parte, analisamos a proposta e criação do PARLAMENTO do MERCOSUL e suas normas e proposições. Por fim, na terceira e última parte, responde às questões propostas.

\section{Integração Regional: aspectos conceituais}

Para se entender o funcionamento do MERCOSUL, é imprescindível pensá-lo à luz do conceito de "integração regional”. Herz \& Hoffman (1994) descrevem este conceito como intrinsecamente interligado aos conceitos de "integração" e "região". "Integração" seria definida pelo processo, no qual atores independentes, em certo momento , se unificam , coexistindo de forma interdependente. Estes atores podem ser governamentais ou nãogovernamentais. "Região" corresponde, dentre outros critérios importantes, ao da localidade territorial.

A integração regional é um processo dinâmico das relações entre atores, que se localizam em territórios próximos. É importante notar que estes atores por conviverem num espaço geograficamente adjacente, compartilham afinidades que são de extrema importância para a coesão do bloco. Estas relações de familiaridade podem ser de natureza sociocultural, política, econômica, dentre outras. Não haverá, por conseguinte, um bloco regional com membros espalhados pelos quatro cantos do globo. Uma estrutura assim não faria sentido para o regionalismo. Esta composição não é estática, e pode ao longo do tempo ser modificada. Ainda assim respeitará a uma correspondência territorial.

O regionalismo é importante, no sentido de promover novos arranjos políticos e cooperação em diversas áreas. Para tal, é de extrema relevância que seus membros tenham 
Artigo original

Hegemonia - Revista Eletrônica de Relações Internacionais do Centro Universitário Unieuro ISSN: 1809-1261

UNIEURO, Brasília, número 5, 2010

uma visão similar, e expectativas de desenvolvimento político-social semelhante. O MERCOSUL, por exemplo, preza sua cláusula democrática, que deve ser respeitada por seus membros, com punição de exclusão do bloco ou instituição, caso algum membro fira os princípios em vigor. Desta forma, a integração regional deixa de ter um rótulo "econômico" ou de "segurança", para assim, expor uma posição ideológica e política, que personaliza o bloco, com suas características intrínsecas.

Ainda conforme Herz \& Hoffman (1994), os processos de integração regional podem, ou não, "gerar" organizações regionais. Quando o fazem, estas adquirem documento constituinte e sede com secretariado permanente, pois deixam de estar no plano das idéias e se materializam. A institucionalização é sempre feita por governos nacionais do Estado, pois só um ator principal no cenário internacional, tem condições de criar outros atores. Isto não significa que o Estado em questão terá voz de comando na organização, pois depois de criada esta terá autonomia para limitar o Estado em suas dependências. As organizações regionais se diferenciam da integração regional pela abrangência de áreas temáticas. As primeiras se restringem à temática específica, e é parte de etapas menores que levarão, ou não, ao todo, que se trata da "integração regional", que abarca várias organizações e seus respectivos objetos.

A integração regional envolve questões sócio-econômicas, políticas e culturais. Remete-se a um fórum de discussões, onde uma variedade de assuntos toma importância regional, criando um clima propício à cooperação entre seus membros a fim de se conseguir alcançar metas comuns a todos os atores. Este é um ambiente favorável aos intercâmbios culturais e políticos, no qual se podem desenvolver atividades que aumentarão a interação entre seus atores e seus nacionais.

Conforme Herz \& Hoffman (1994), as organizações regionais funcionais, de segurança, a integração regional, e os acordos econômicos podem surgir simultaneamente. Este fato se intitula "regionalismo". Houve duas fases diferentes deste fenômeno, o "regionalismo aberto" e "regionalismo fechado". Este gera o protecionismo no nível regional. 
Artigo original

Hegemonia - Revista Eletrônica de Relações Internacionais do Centro Universitário Unieuro ISSN: 1809-1261

UNIEURO, Brasília, número 5, 2010

Aquele se refere às etapas intermediárias para a liberalização multilateral, quando os blocos promoveram o multilateralismo entre si e entre seus membros.

A integração regional "nasceu" no contexto Pós-Guerra, quando as nações sentiram a necessidade de se ajustarem à nova ordem econômica mundial. Herz \& Hoffman (1994), analisa os anos 70 como a década referente à primeira onda do regionalismo: o regionalismo fechado, como estratégia de desenvolvimento não oferecida pelo GATT $^{2}$, organismo multilateral. No Pós-guerra Fria o multilateralismo aberto se destacou, na segunda parte da década de 1980, mais por manutenção da ordem e estabilidade da política internacional, que por buscar desenvolvimento.

Além disso, é importante apontar que existem códigos e normas a serem seguidos no âmbito da integração. Estas normativas designam as relações entre os atores e promovem o intercâmbio e cooperação entre os mesmos. Os Estados, então, podem estender os braços de seus parlamentos a fim de que haja uma interação entre os mesmos e internalização jurídicas de interesse coletivo no âmbito regional.

Segundo José Everaldo Ramalho (2008), o cenário internacional contemporâneo, globalizado, apresenta tendência regionalista e multilateralista. O regionalismo tende à formação de blocos econômicos, enquanto o multilateralismo prevê um espaço mais amplo para as negociações (OMC- Organização Mundial do Comércio). Estas disposições se derivam das condições de natureza política e econômicas entre as nações. A regionalização é a forma dos países obterem poder de barganha, tornando-os mais competitivos. Portanto, a integração econômica não é um fim em si mesmo. Pois se constitui instrumento de inserção dos países-membros no mercado internacional.

\footnotetext{
2 GATT-Acordo Geral sobre Tarifas foi estabelecido em 1947. tendo em vista harmonizar as políticas aduaneiras dos Estados signatários. Está na base da criação da Organização Mundial de Comércio. É um conjunto de normas e concessões tarifárias, criado com a função de impulsionar a liberalização comercial e combater práticas protecionistas, regular, provisoriamente, as relações comerciais internacionais.Fonte: http://pt.wikipedia.org/wiki/GATT
} 
Artigo original

Hegemonia - Revista Eletrônica de Relações Internacionais do Centro Universitário Unieuro ISSN: 1809-1261

UNIEURO, Brasília, número 5, 2010

A formação de blocos econômicos é uma tendência de um modelo de integração regional característica do mundo globalizado, quando um agrupamento de diversos países de uma região com laços econômicos ,une-se em prol do desenvolvimento, da integração e da liberalização econômica. Os blocos econômicos se caracterizam pela procura por fórmulas breves de acordo entre seus parceiros que permita negociar a defesa de interesses econômicos e conseguir a promoção integrada de desenvolvimento. Em tempos de crise das instituições de natureza multilateral, o regionalismo continua sendo aceito como uma alternativa viável para manutenção da ordem e estabilidade da política internacional.

\section{A Integração na América do Sul}

No histórico sul-americano, houve vários projetos $\mathrm{e}$ tentativas integracionistas. $\mathrm{O}$ regionalismo continental se apresentou tanto na versão pan-americana quanto na versão latino-americanismo. O pan-americanismo segundo Souto Maior (2003), tenderia à formação de laços especiais entre todas as nações do Hemisfério Ocidental, e o latino-americanismo, que, sem rejeitar frontalmente o primeiro, dá prioridade às relações entre os países da América Latina. Os dois convivem no continente desde o século XIX, mas buscam objetivos diferentes.

Um dos principais precursores do regionalismo latino-americanismo foi Simon Bolívar. Bolívar em fins de sec. XIX desejou criar três federações no continente, dentre estas, uma na América do Sul que não obteve sucesso, pois os Estados nacionais latino-americanos ainda estavam em processo de consolidação. Em 1948, com a criação da Organização dos 
Artigo original

Hegemonia - Revista Eletrônica de Relações Internacionais do Centro Universitário Unieuro

ISSN: 1809-1261

UNIEURO, Brasília, número 5, 2010

Estados Americanos (OEA) ${ }^{3} \cdot$, e da Associação Latino-Americana de Livre- Comércio $(\text { ALALC })^{4}$, em 1960, a doutrina do pan-americanismo se consolidou.

Para Herz \& Hoffman (1994), o projeto de integração no âmbito da ALALC partiu do pressuposto de que a integração deveria ser implementada a partir da esfera econômica. Esta hipótese se baseou em princípios funcionalistas em voga neste tempo e por influência da CEPAL ${ }^{5}$ (Comissão Econômica para América Latina). Em 1980, a ALADI (Associação Latino-Americana para o Desenvolvimento de Integração) substituiu a ALALC. Apesar da existência da integração, os Estados do Cone Sul não priorizaram a mesma. A ALADI fracassou possivelmente por ser composta por um grande número de países heterogêneos.

A promoção da integração sub-regional se fortaleceu no final da década de 1980, durante a segunda onda de regionalismo. Foi neste contexto que foi lançada a pedra fundamental do MERCOSUL. A definição do Cone Sul, região específica com este formato geográfico dos Estados- Parte do MERCOSUL é recente. Esta região sempre foi cenário de conflitos hegemônicos entre Brasil e Argentina. Após a década de 1970, as duas nações passaram a se aproximar e iniciar cooperação.

3 OEA- Organização dos Estados Americanos (OEA) é uma organização internacional criada em 1948 , com sede em Washington (Estados Unidos), cujos membros são as 35 nações independentes das Américas. A Organização dos Estados Americanos foi fundada em 30 de abril de 1948, constituindo-se como um dos organismos regionais mais antigos do mundo. Fonte: http://pt.wikipedia.org/wiki/OEA.

ALALC- Associação Latino-Americana de Livre Comércio foi uma tentativa não bem sucedida de integração comercial da América latina na década de 60 . Os membros eram Argentina, Brasil ,Chile, México, Paraguai, Peru, e Uruguai. Pretendiam criar uma área de livre comércio na América Latina.Em 1970, a ALALC se expandiu com a adesão de novos membros: Bolívia, Colômbia, Equador, e Venezuela. Em 1980, se tornou ALADI. Permaneceu com essa composição até 1999, quando Cuba passou a ser membro.Fonte: http://pt.wikipedia.org/wiki/Alalc.

5 CEPAL-A Comissão Econômica para a América Latina e o Caribe (CEPAL) foi criada em 1948 pelo Conselho Econômico e Social das Nações Unidas com o objetivo de incentivar a cooperação econômica entre os seus membros. Ela é uma das cinco comissões econômicas da Organização das Nações Unidas (ONU) e possui 43 estados e oito territórios não independentes como membros. Além dos países da América Latina e Caribe fazem parte da CEPAL, o Canadá, França, Japão, Países Baixos, Portugal, Espanha, Reino Unidoe Estados Unidos da América. 
Artigo original

Hegemonia - Revista Eletrônica de Relações Internacionais do Centro Universitário Unieuro

ISSN: 1809-1261

UNIEURO, Brasília, número 5, 2010

\section{MERCOSUL: Origem e evolução}

Segundo Herz \& Hoffman (1994), foi durante os governos militares, que os dois Estados começaram seu entendimento com o Acordo Multilateral Corpus-Itaipu, em outubro de 1979, para solução da incompatibilidade de construção das usinas hidrelétricas argentina e brasileira. Após a transição democrática, Raul Alfonsín, presidente argentino e Tancredo Neves, presidente brasileiro; expuseram vontade de criar um projeto de integração de cunho mais político. José Sarney, dando continuidade ao projeto de Tancredo, assinou juntamente à Alfonsín, em novembro de 1985, a Declaração de Iguaçu.

A Declaração de Iguaçu constituiu a Comissão Mista Binacional de Alto Nível, responsável por acelerar o processo de integração bilateral. Este foi o ponto de partida para criação do MERCOSUL. A partir daí, com Carlos Meném e Fernando Collor de Mello na Argentina e Brasil, respectivamente, ambos os países se prontificaram a praticar um mercado comum e assinaram a Declaração de Buenos Aires, em 1990. A relação bilateral evoluiu com a entrada posterior do Uruguai e Paraguai, e se solidificou após a adesão ao Tratado de Assunção ${ }^{6}$, em março de 1991. O bloco adquiriu personalidade jurídica através da assinatura do Protocolo de Ouro Preto ${ }^{7}$, em dezembro de 1994 e foi reconhecido como uma organização internacional após um ano da adesão. O MERCOSUL é formado por quatro países membros:

\footnotetext{
6 O Tratado de Assunção foi um tratado assinado em 26 de março de 1991, entre a Argentina, Brasil, Paraguai e Uruguai, com o objetivo de criar um mercado comum entre os países acordados formando então, o que popularmente foi chamado de Mercosul, Mercado comum do sul ou em castelhano, Mercado comum del sur. Fonte: http://pt.wikipedia.org/wiki/Tratado_de_Assunção

$7 \quad$ O Protocolo de Ouro Preto é o primeiro segmento do Protocolo de Assunção que estabelece as bases institucionais para o Mercosul. Denominou-se assim porque foi assinado em 16 de dezembro de 1994 na cidade histórica de Ouro Preto, em Minas Gerais, Brasil, e é complementar as bases institucionais do Tratado de Assunção.Fonte: http://pt.wikipedia.org/wiki/Protocolo_de_Ouro_Preto
} 
Artigo original

Hegemonia - Revista Eletrônica de Relações Internacionais do Centro Universitário Unieuro ISSN: 1809-1261

UNIEURO, Brasília, número 5, 2010

Brasil, Argentina, Uruguai e Paraguai e por três associados: Bolívia, Chile e Venezuela, Colômbia, Equador e Peru.

Herz \& Hoffman (1994) salientam a aspectos interessantes do MERCOSUL, quando aludem à importância dada pelo bloco à cláusula democrática do bloco e a Declaração de Zona de Paz. Em 1996, com a tentativa de golpe por parte do General Oviedo, no Paraguai, os Estados- Partes do MERCOSUL institucionalizaram o compromisso democrático com a Declaração sobre o Compromisso Democrático. Este compromisso foi formalmente incorporado ao Tratado de Assunção, através da conclusão do Protocolo de Ushuaia ${ }^{8}$ em julho de 1998, que entrou em vigor em janeiro de 2002. Após indícios de ameaças mundiais de proliferação de armas de destruição em massa, os Estados-Parte do MERCOSUL decidiram assumir um compromisso.

Segundo Albuquerque (2005), esta cláusula democrática surgiu graças aos entendimentos entre os ex-presidentes Alfonsín e Sarney, nos dois regimes democráticos vindos de uma recente experiência militar e autoritária, e que viam nesse estreitamento da cooperação entre os dois países, Brasil e Argentina, a possibilidade da defesa da democracia de ambos os países no novo contexto.

Para o autor, um dos motivos que levaram à criação do MERCOSUL foi o contexto financeiro argentino e brasileiro. Os dois países tinham passando por situações de fragilidade e estavam vulneráveis a fatores externos, como questões da dívida externa e super inflação. A Argentina estava passando por ajustes econômicos e por um programa de conversibilidade da moeda e o Brasil estava partindo para um processo de abertura comercial unilateral, e ambos os países dependiam de um suporte externo alcançado graças ao MERCOSUL.

$8 \quad$ O Protocolo de Ushuaia é um protocolo assinado em 24 de julho de 1998 na cidade argentina de Ushuaia pelos quatro Estados-membros do Mercosul (Argentina, Brasil, Uruguaie Paraguai) mais dois Estadosassociados (Bolívia e Chile) reafirmando o compromisso democrático entre os Estados assinados.Fonte: http://pt.wikipedia.org/wiki/Protocolo_de_Ushuaia 
Artigo original

Hegemonia - Revista Eletrônica de Relações Internacionais do Centro Universitário Unieuro ISSN: 1809-1261

UNIEURO, Brasília, número 5, 2010

Albuquerque (2005) considera o destino pelo MERCOSUL para o Brasil multidimensional. O MERCOSUL é o marco fundador de nossas relações internacionais. Estas diversas dimensões de destino platino do Brasil estão interligadas às Actas de Iguazu ${ }^{9}$ e no Tratado de Assunção. É através do MERCOSUL que o Brasil poderá se sobressair nas dimensões o comércio, da segurança, da cultura, dos direitos e valores globais.

O objetivo do MERCOSUL é criar um mercado comum com livre circulação de bens, serviços e fatores produtivos. Segundo Ramalho (2008), complementando esse objetivo maior busca-se a adoção de uma política externa comum, a coordenação de posições conjuntas em foros internacionais, a formulação conjunta de políticas macroeconômicas e setoriais e, por fim a harmonização das legislações nacionais, com vistas a uma maior integração. O autor afirma que o MERCOSUL é, desde $1^{\circ}$ de janeiro de 1995, uma União Aduaneira, mas o objetivo dos países que o integram, e que está consubstanciado no primeiro artigo do Tratado de Assunção, é a construção de um Mercado Comum.

A adesão ao bloco é feita por meio de aprovação unânime pelos Estados-parte e o pré-requisito é ser membro da ALADI. Para se tornar membro associado do MERCOSUL, o país deve ser membro da ALADI e ter concluído acordo de livre-comércio com o bloco. A regulamentação de adesão de membros associados possibilitou a participação de países em reuniões dos órgãos do MERCOSUL como observadores.

Os principais órgãos do MERCOSUL são: o Conselho do Mercado Comum, o Grupo Mercado Comum, a Comissão de Comércio, a Comissão Parlamentar Conjunta, o Foro Consultivo Econômico-Social, o Tribunal Permanente de Revisão e a Secretaria Administrativa. O Grupo Mercado Comum (GMC), órgão decisório executivo do Mercosul, responsável de fixar os programas de trabalho, e de negociar acordos com terceiros em nome do MERCOSUL, por delegação expressa do CMC. O GMC se pronuncia por Resoluções, e está integrado por representantes dos Ministérios de Relações Exteriores e de Economia, e dos

\footnotetext{
9 Protocolo assinado pelos presidentes Alfonsí e Sarney prevendo a criação de uma área de libre comércio. Fonte : Albuquerque (2008)
} 
Artigo original

Hegemonia - Revista Eletrônica de Relações Internacionais do Centro Universitário Unieuro ISSN: 1809-1261

UNIEURO, Brasília, número 5, 2010

Bancos Centrais dos Estados Parte. A Comissão de Comércio do Mercosul (CCM), um órgão decisório técnico, é o responsável por apoiar o GMC no que diz respeito à política comercial do bloco Mercosul. Se pronuncia por Diretivas. A Comissão Parlamentar Conjunta do Mercosul (CPC), era o órgão representativo dos parlamentos no Mercosul e foi substituído pelo Parlamento do Mercosul ${ }^{10}$.

Segundo Herz \& Hoffman, o Foro Consultivo Econômico -Social é um órgão de representação da sociedade criado pelo MERCOSUL.O Foro funciona com representantes de trabalhadores, empresários e consumidores e emite recomendações ao Grupo Mercado Comum. O Tribunal Permanente de Revisão foi estabelecido pelo MERCOSUL através do Protocolo de Olivos, para solucionar controvérsias.

Nosso objeto de estudo se focará na Comissão Parlamentar Conjunta (CPC) do MERCOSUL e Parlamento do MERCOSUL. De acordo com o art. 22 do Protocolo de Ouro Preto, a CPC operou como "órgão representativo dos Parlamentos dos Estados Partes no âmbito do MERCOSUL".

\section{Parlamento do MERCOSUL: Comissão Parlamentar Conjunta do MERCOSUL}

A Comissão Parlamentar Conjunta foi fundada pelo Tratado de Assunção, e o Protocolo de Ouro Preto. Foi um órgão representativo dos Parlamentos dos Estados Partes no âmbito do MERCOSUL, composto por número igual de parlamentares representantes de cada país do bloco e encarregados pelos respectivos Parlamentos nacionais, de acordo com seus procedimentos internos. Cada Estado-membro possui uma Representação Nacional em suas Casas Legislativas. Segundo Ramalho (2008), o Protocolo de Ouro Preto estabeleceu que a Comissão Parlamentar Conjunta encaminhasse, por intermédio do Grupo Mercado Comum,

\footnotetext{
10 Informações obtidas sobre o Conselho do Mercado Comum, o Grupo Mercado Comum, a Comissão de Comércio e a Comissão Parlamentar Conjunta no site: www.wikipedia.com.br
} 
Artigo original

Hegemonia - Revista Eletrônica de Relações Internacionais do Centro Universitário Unieuro

ISSN: $1809-1261$

UNIEURO, Brasília, número 5, 2010

as decisões e resultados do trabalho parlamentar conjunto, sob a forma de Recomendações ao Conselho do Mercado Comum para que este, por sua vez, os transformasse em políticas públicas setoriais, quando fosse o caso.

A Comissão teria, ainda, segundo seu Regimento Interno, caráter consultivo, deliberativo e de formulação de Declarações ${ }^{11}$, de Disposições ${ }^{12}$ e de Recomendações ${ }^{13}$. Dentre as atribuições da CPC, destacam-se o arranjo de um clima favorável à criação do Parlamento do MERCOSUL.

A CPCM foi responsável pelas questões parlamentares e pelo acompanhamento do processo de integração, assim como por manter os Congressos Nacionais informados de cada passo da integração e de assuntos concernentes ao MERCOSUL ,além de elaborar Políticas Legislativas de Integração e realização de estudos necessários para a harmonização das legislações dos Estados Partes. Prontificava a entrada em vigor das normas provindas dos órgãos do MERCOSUL.

11 Declarações são documentos de cunho político, emitidas em conseqüência da pauta política regional, como, por exemplo, por força dos enfrentamentos locais em cada país membro que, de alguma maneira, conflitam com o princípio do compromisso democrático firmado por todos em respeito ao Protocolo de Ushuaia. Nesse sentido, a CPC emitiu Declarações lamentando o golpe de Estado no Peru, em 1992, e ameaçando o Paraguai de exclusão do bloco na tentativa de golpe de Estado, em 1999, em decorrência do assassinato do Vice-Presidente paraguaio, ambas as iniciativas em total desacordo com a plena vigência das instituições democráticas, condição assumida pelos integrantes do MERCOSUL, membros plenos ou associados, e indiscutivelmente, essenciais para o desenvolvimento dos processos de integração entre os Estados que assinaram o Protocolo de Ushuaia. (Ramalho, 2008).

12 Disposições representam decisões internas da CPC destinadas a regulamentar procedimento interno da própria Comissão, como, por exemplo, as Disposições 12/05 e 13/05 que aprovaram a criação da Unidade de Gestão do Projeto de Cooperação União Européia - Comissão Parlamentar Conjunta para Apoio à Instalação do Parlamento do MERCOSUL, e a Disposição 02/06, que aprovou o Programa de Introdução e Treinamento no MERCOSUL, dirigido a parlamentares e técnicos da Assembléia Nacional Bolivariana da Venezuela, recém admitida como país membro do bloco, e que se encontra no momento em processo de adesão. (Ramalho, 2008).

13

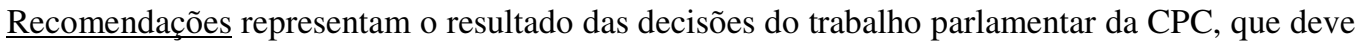
encaminhá-las ao Grupo Mercado Comum para que este, a sua vez, delas dê conhecimento ao Conselho do Mercado Comum que, quando for o caso, as transformará em políticas públicas regionais. Por exemplo, o aperfeiçoamento do sistema de incorporação da normativa. MERCOSUL ao ordenamento jurídico dos Estados Partes, pode-se supor ser o resultado de decisão da CPC de recomendar ao Conselho do Mercado Comum a conveniência de conferir maior agilidade e previsibilidade ao processo de incorporação de normas que garantirão a segurança jurídica exigida pelos negócios empreendidos por cidadãos, empresas e Estados no espaço geográfico do MERCOSUL. (Ramalho, 2008). 
Artigo original

Hegemonia - Revista Eletrônica de Relações Internacionais do Centro Universitário Unieuro ISSN: 1809-1261

UNIEURO, Brasília, número 5, 2010

Tem a capacidade para aprovar normas de direito da integração, posteriormente enviadas à importância dos Parlamentos Nacionais. Estabelece o intercâmbio de cooperação com os Parlamentos de terceiros países e com outras instituições dos demais planos de integração regional. Estabelece relações e acordos sobre cooperação e assistência técnica com órgãos públicos e privados, de nível nacional, regional, supranacional e internacional. Por fim, a CPCM poderá estabelecer outras atribuições dentro do âmbito do Tratado de Assunção e do Protocolo de Ouro Preto, além das citadas acima.

A Comissão Parlamentar Conjunta do MERCOSUL constituiu várias subcomissões com o objetivo dinamizar a análise dos temas relacionados com o processo de integração e também sobre Decisões, Resoluções, Diretrizes e Propostas derivadas dos órgãos institucionais do MERCOSUL. As subcomissões são integradas por até quatro parlamentares de cada Estado Parte e seus suplentes. Podem ser instituídas, alteradas ou suprimidas pela Comissão, desde que a mesma respeite os limites de sua atuação de acordo com o Tratado de Assunção, o Protocolo de Ouro Preto e com o próprio Regimento Interno.

De acordo com Ramalho (2008), as decisões da Comissão somente podem ser tomadas por consenso das delegações de todos os Estados- Parte, promulgado pelo voto da maioria de seus integrantes acreditados pelos respectivos Parlamentos. A presidência Pro Tempore da CPC é exercida por um período rotativo de seis meses, e as duas sessões anuais ordinárias serão sempre realizadas no território do Estado Parte que as presidir. A CPC pode também reunir-se por convocação extraordinária dos presidentes de cada Representação Nacional.

A CPC também poderá se reunir semestralmente com o Conselho do Mercado Comum, em uma de suas reuniões ordinárias ou extraordinárias, para avaliar os progressos da integração durante o estágio da Presidência Pro Tempore. Todos os documentos submetidos à consideração da Mesa Executiva ou do Plenário deverão estar redigidos em português e espanhol, idiomas oficiais do MERCOSUL.

O autor conclui sua abordagem sobre as funções e competências da CPC, ressaltando que a implementação das Seções Nacionais no âmbito dos Congressos dos Estados Partes encontra-se processo de construção. Há a polêmica sobre a possibilidade das Representações 
Artigo original

Hegemonia - Revista Eletrônica de Relações Internacionais do Centro Universitário Unieuro ISSN: 1809-1261

UNIEURO, Brasília, número 5, 2010

Nacionais abrigarem ou não deputados e senadores numa só comissão mista, como é o caso do Brasil, ou se optará por comissões separadas, que se fundirão apenas para os trabalhos conjuntos da Comissão Parlamentar Conjunta.

\section{A criação do Parlamento do MERCOSUL}

A criação do Parlamento do MERCOSUL teve sessão inaugural realizada, no dia 14 de dezembro de 2006, em Brasília, no Congresso Nacional, na presença dos representantes dos cinco Estados Partes - Argentina, Brasil, Paraguai, Uruguai e Venezuela - e dos membros associados. O Parlamento do MERCOSUL substituiu a Comissão Parlamentar Conjunta do MERCOSUL.

A sede do PM é em Montevidéu e há uma sessão parlamentar por mês. A composição dessa Casa é de 18 parlamentares por país, e para ocupação dos cargos há um processo de transição. Os parlamentares de cada país serão indicados pelo seu Parlamento e de acordo com o seu calendário eleitoral. Até o final de 2010, terão sido realizadas eleições nacionais em todos os países para a escolha dos 18 representantes. Somente em 2014 estão previstas eleições específicas para o Parlamento do MERCOSUL, e simultâneas em todos os países do Bloco. O Brasil tem a sua representação no Parlamento por meio de nove deputados e nove senadores escolhidos pelo Congresso Nacional.

Os princípios do Parlamento se baseiam na representação dos povos do MERCOSUL, primando pelo respeito à pluralidade ideológica e política com a condição de que os mesmos estejam de acordo com os princípios da democracia, da liberdade, da paz e do desenvolvimento sustentável. Segundo Ramalho (2008), a estrutura institucional do MERCOSUL se inspirou no modelo da união aduaneira européia, porém com uma abordagem aptada às condições políticas próprias de países em desenvolvimento.

A criação do Parlamento do MERCOSUL modificou a configuração institucional do MERCOSUL, ao dar vazão à representação de interesses particulares e da sociedade civil, 
Artigo original

Hegemonia - Revista Eletrônica de Relações Internacionais do Centro Universitário Unieuro

ISSN: 1809-1261

UNIEURO, Brasília, número 5, 2010

pois estimula a participação dos atores da sociedade civil no processo de integração e na formação de uma consciência integracionista na região. Para Ramalho (2008), o Parlamento do MERCOSUL é um foro de debates, seminários e audiências públicas sobre os temas da integração, importante para os setores da sociedade civil, e constitui o canal de comunicação entre as populações e as instâncias negociadoras da integração. A participação da sociedade civil se mostra essencial por assegurar a transparência do processo de construção do bloco e contribuir para que as normas do MERCOSUL passem por amplo debate antes de serem adotadas. O Parlamento contribui ainda para a qualidade técnica das normas do MERCOSUL através mecanismo da consulta parlamentar ${ }^{14}$. e constitui um espaço para debates sobre as normas em negociação com adoção de decisões tomadas por voto individual dos membros das delegações. O mesmo define um modelo de integração democrático que exprime uma nova concepção sobre a política regional.

O Parlamento representa a construção do espaço político regional que objetiva fortalecer e melhorar a qualidade das democracias nos países do bloco, além de promover políticas regionais de integração fronteiriça sem barreiras, a livre circulação de pessoas, bens e serviços. É através deste que se alcançará a correção gradual das assimetrias, através de parcerias e cooperação nas políticas públicas que tenham o cidadão como alvo principal das iniciativas integracionistas.

Segundo a publicação conjunta da Comissão Parlamentar Conjunta do MERCOSUL e da Fundação Konrad Adenauer ${ }^{15}$, a criação do Parlamento do MERCOSUL expõe a vontade

\footnotetext{
14 O mecanismo de consulta parlamentar é reproduzido no Artigo 4, inciso 12 do Protocolo, e estabelece o prazo máximo de cento e oitenta (180) dias corridos para que os Congressos Nacionais dos Estados Partes do Mercosul se manifestem sobre as normas que tenham sido adotadas pelo Conselho do Mercado Comum consoante o parecer emitido pelo Parlamento regional, no momento de sua negociação. $\mathrm{O}$ mesmo inciso ressalva que, se dentro do prazo desse procedimento preferencial, o Parlamento do Estado Parte não aprovar a norma, esta deverá ser reenviada ao Poder Executivo, que a encaminhará à reconsideração do órgão correspondente do MERCOSUL. Por sua vez, os Parlamentos Nacionais deverão adotar as medidas necessárias para a instrumentalização do procedimento acima referido, em conformidade com as suas respectivas normas regimentais. Por meio desse mecanismo, o Parlamento do MERCOSUL contribuirá para solucionar a grave fragilidade de que padece o bloco, que se traduz, precisamente, no baixo índice de normas da integração efetivamente incorporadas aos ordenamentos jurídicos nacionais.

15 Hacia el Parlamento del Mercosur, Una Recopilación de documentos, $2^{\circ}$ edição, fundação Konrad Adenauer, Oficina Uruguai, 2006.
} 
Artigo original

Hegemonia - Revista Eletrônica de Relações Internacionais do Centro Universitário Unieuro ISSN: 1809-1261

UNIEURO, Brasília, número 5, 2010

regional de integração política; materializa a vontade da integração como projeto político estratégico, com perspectiva histórica e com modelo de desenvolvimento integral; significa que alcançar um mercado comum não é condição suficiente para que a integração aconteça, pois o perfil da integração no século XXI inclui uma integração econômica, complementar e solidária, social e cultural com a adoção em áreas estratégicas de diretrizes políticas comuns num cenário internacional complexo e assimétrico; estabelece um espaço de análise e reelaboração do conceito de soberania através da atuação conjunta dos Estados-Parte; retoma o conteúdo democrático; consolida o princípio da representatividade e participação cidadã no processo de integração; conforma um espaço permanente da política e da cidadania na estrutura institucional do MERCOSUL e por fim, aperfeiçoa o sistema de tomada de decisões e o processo normativo do MERCOSUL.

\section{Considerações Finais}

Este estudo propôs uma reflexão sobre a integração regional, especificamente sobre o MERCOSUL (Mercado Comum do Sul) e sua importância em nível regional e internacional. De forma sucinta, buscou apontar a relevância do Parlamento do MERCOSUL como fórum de discussões de questões pertinentes ao processo de integração regional e efetivação da incorporação normativa dos ordenamentos dos Estados-Parte, trazendo consigo o aperfeiçoamento e consolidação do bloco.

Esse trabalho teve como objetivo principal analisar a importância do Parlamento do MERCOSUL para o Bloco e sua consolidação. Como objetivo específico, pretende-se: compreender o contexto e razões do processo de integração; conhecer a dinâmica do bloco nas Relações Internacionais e por fim analisar a evolução do MERCOSUL com a criação do Parlamento. 
Artigo original

Hegemonia - Revista Eletrônica de Relações Internacionais do Centro Universitário Unieuro ISSN: 1809-1261

UNIEURO, Brasília, número 5, 2010

Nesse sentido, o problema central do estudo refere-se à importância da constituição de um Parlamento, que de fato possa atender às necessidades do MERCOSUL e dos mercosulinos. Daí as perguntas: qual o papel da integração regional para o intercâmbio comercial, político e cultural? Como a internalização de leis nacionais pode interferir neste intercâmbio?Como o Parlamento do MERCOSUL pode aproximar os nacionais de seus Estados- Parte entre si e fazê-los sentir-se parte do bloco?Quais os aspectos positivos da criação do Parlamento neste Bloco?

O papel da integração regional para o intercâmbio comercial, político e cultural é instituir um fórum de discussões, no qual uma série de temas se tornam objetos de interesse regional, facilitando a cooperação entre seus os Estados-Parte com alvos comuns a todos os atores. Desta forma a integração regional se mostra responsável pelo estabelecimento de um ambiente favorável aos intercâmbios culturais e políticos, no qual se podem desenvolver projetos que terão poder de influência mútua entre os Estados membros e a sociedade civil da respectiva região.

A internalização de leis nacionais pode interferir neste intercâmbio, na medida em que aproxima os Estados-Parte do MERCOSUL e mercosulinos através dos códigos e normas adotados no âmbito da integração que interferem nas relações entre os parlamentos nacionais e cidadãos, ou seja, representantes e representados, pois são de interesse coletivo no âmbito regional. Desta forma, ao internalizarem leis, os países e mercosulinos interagem entre si, pois compartilham um conjunto de normas jurídicas estabelecidas através de cooperação entre mesmos.

O Parlamento do MERCOSUL pode aproximar os nacionais de seus Estados-Parte entre si e fazê-los sentir-se parte do bloco através do acesso democrático da sociedade civil, pois o bloco deixou de ser dominado pelas forças intergovernamentais, e passou a compartilhar projetos sociais, econômicos, culturais e jurídicos com os mercosulinos. Fazendo assim com que as medidas integracionistas sejam diretamente voltadas para os mercosulinos e discutidas pelos mesmos. Portanto o Parlamento é um fórum de discussões, no 
Artigo original

Hegemonia - Revista Eletrônica de Relações Internacionais do Centro Universitário Unieuro ISSN: 1809-1261

UNIEURO, Brasília, número 5, 2010

qual a sociedade civil pode interagir com o MERCOSUL e através desta interação esperam-se o surgimento de uma identidade mercosulina.

Os aspectos positivos da criação do Parlamento neste bloco são diversos e numerosos. Dentre todos, pode-se citar a possibilidade de maior aproximação entre os movimentos sociais nacionais dos países do MERCOSUL, por meio de pautas comuns de reivindicação e de acordo com os princípios de autodeterminação dos povos, de igualdade entre os Estados, de busca de solução pacífica dos conflitos e de prevalência dos direitos humanos. Com a atuação do Parlamento do MERCOSUL pode-se vislumbrar uma diminuição na assimetria entre os países membros do Bloco através do diálogo entre instituições do Bloco e órgãos nacionais de cada Estado membro. O PM fortalece o princípio democrático, através da participação dos legislativos nacionais, produzindo uma participação representativa dos cidadãos nacionais. Também é muito importante na incorporação de normas e regras promovendo a segurança jurídica para o bloco e projetando transparência.

Existe uma tendência ao destaque de aspectos dificultantes para a evolução do MERCOSUL. A adesão da Venezuela que, embora ainda sem direito a voto, é objeto de polêmica devido à postura radical de luta contra o imperialismo capitalista norte-americano por parte do presidente Hugo Chávez. Percebe-se que há uma confusão sobre a adesão do Estado, pois as pessoas confundem o mesmo com a pessoa de seu presidente. O presidente Hugo Chávez, dará lugar a outro presidente enquanto o Estado da Venezuela continuará existindo. Portanto a adesão deste país ao MERCOSUL pode ter correspondência à determinada política governamental até o fim do mandato do presidente correspondente.

Devido às assimetrias econômicas entre os países membros, há diferentes posturas no que diz respeito ao grau de institucionalização exigido pelo projeto de integração, e também quanto criação de órgãos supranacionais. Estas posições predispuseram o MERCOSUL a praticar uma integração mais pragmática e realista, e confrontar os cenários internos e externos, com o objetivo de ampliar, fortalecer e consolidar o bloco nos níveis regional e internacional com uma estrutura institucional ativa. 
Artigo original

Hegemonia - Revista Eletrônica de Relações Internacionais do Centro Universitário Unieuro ISSN: 1809-1261

UNIEURO, Brasília, número 5, 2010

O modelo de integração seguido pelo MERCOSUL teve inspiração no europeu, que conta com mais de cinquienta anos e já se deparou com inúmeros problemas, porém se tornou a União Européia ${ }^{16}$. É importante ressaltar que o MERCOSUL tem alcançado uma indiscutível evolução institucional desde a sua criação até os dias atuais, apesar da assimetria entre países e demais entraves existentes, e que fazem parte de qualquer tentativa de integração. O bloco é muito jovem, tem apenas dezoito anos e aos dezesseis já ganhou um parlamento, isto demonstra um crescimento e institucionalização louváveis.

\section{Bibliografia}

ALBUQUERQUE, José Augusto Guilhon. RELAÇÕES INTERNACIONAIS CONTEMPORÂNEAS-A Ordem mundial depois da Guerra Fria. $2^{\mathrm{a}}$ Ed. Vozes. Petrópolis, 2007.

HERZ, Mônica, Hoffman, Andrea Ribeiro. Organizações Internacionais: História e Práticas. 1 ${ }^{a}$ Ed. Elsevier. Rio de Janeiro, 2004.

MAIOR, Luiz A. P. Souto. O BRASIL EM UM MUNDO EM TRANSIÇÃO. $2^{\mathrm{a}}$ Ed. UNB/IBRI, Brasília, 2003.

RAMALHO, JOSÉ EVERALDO. FUNDAMENTOS DA INTEGRAÇÃO REGIONAL: O MERCOSUL. Curso online 2008 pela Interlegis. www.interlegis.gov.br

\footnotetext{
16 (UE), anteriormente designada por Comunidade Económica Europeia (CEE; no Brasil, Comunidade Econômica Europeia) e Comunidade Europeia (CE), é uma organização internacional constituída actualmente por 27 estados membros. Foi estabelecida com este nome pelo Tratado da União Europeia(normalmente conhecido como Tratado de Maastricht) em 1992, mas muitos aspectos desta união já existiam desde a década de 50. A União tem sedes em Bruxelas, Luxemburgo e Estrasburgo.Fonte:_pt.wikipedia.org/wiki/União_Europeia.
} 
Artigo original

Hegemonia - Revista Eletrônica de Relações Internacionais do Centro Universitário Unieuro ISSN: 1809-1261

UNIEURO, Brasília, número 5, 2010

Hacia el Parlamento del Mercosur: Una Recopilación de documentos. $2^{\circ}$ edição, fundação Konrad Adenauer, Oficina Uruguai, Fundación Konrad-Adenauer/Oficina Uruguay. Montevideo, 2006.

Sites consultados:

Parlamento Del Mercour: http://www.parlamentodelmercosur.org

Wikipedia: http://www.wikipedia.com.br 